\title{
Research on Impact Mechanism willingness to cannibalize on Industry Technology innovation Yong-ming PAN ${ }^{1, a}$, Qi-ran $Y U^{2, b}$ \\ ${ }^{1}$ Tianjin University of Technology, School of Management, Tianjin, China \\ ${ }^{2}$ Tianjin University of Technology, School of Management, Tianjin, China \\ a pym_tj@sina.com , ${ }^{\mathrm{b}} 347316485 @ q q . c o m$
} Keywords: Industry Technology innovation, Willingness to cannibalize, The core competence of
enterprises

\begin{abstract}
The strong willingness to cannibalize from the internal of industrial enterprise can improve innovation performance through the cannibalization of the core competence of industrial enterprise. Through the comparative analysis of the industrial enterprise's innovation process with or without the cannibalization, we can see that the cannibalization of the industrial enterprise's core competence have obvious influence on the industrial enterprise innovation performance. The cannibalization of the industrial enterprise's core competence can improve the industry innovation performance.
\end{abstract}

\section{Product cannibalization and willingness to cannibalize}

Innovation is an effective way to improve the core competitiveness of enterprise. The core competence of enterprise for their own willingness to cannibalize is a key factor in enterprise innovation, therefore it is necessary for enterprise to cultivate strong willingness to cannibalize from within to push the original product innovation.

Cannibalization. Cannibalization refers to the phenomenon of the development of new products or innovation. So the research on the phenomenon of cannibalize mainly relates to product cannibalization, namely the enterprise offers new products to reduce the degree of enterprise product sales phenomenon $^{[1]}$.

willingness to cannibalize. Chandy and Tellis (1998) first suggested the concept of willingness to cannibalize: enterprises are ready to reduce the degree of the existing or potential value investment ${ }^{[2]}$.The willingness to cannibalize is rooted in the enterprise culture, values and concept of senior policymakers attitude qualities ${ }^{[3]}$. Montalvo (2006) argues that under the goal of enterprise strategic planning and technology development, the intention is the first enterprise innovation behavior prediction variables ${ }^{[4]}$.In this paper, on the basis of summarizing literature, it intends to distinguish two dimensions as resources willingness to cannibalize and practices.

Cannibalization of the enterprise's core competence. Enterprise core competence cannibalization is derived from the enterprise interior strong and will, is the enterprise to the transformation of enterprise resources and enterprise practice. This transformation is helpful to the development of new products into new markets. As a result, companies create a new core ability for new product development, so that we can improve the likelihood of success in new markets.

\section{enterprise diversification expansion under traditional model}

Enterprises create the core assets to produce the products on the market to create profits through own core competence during the explicit process: if the enterprises' core ability and core assets are set respectively as $\mathrm{M}$ and $\mathrm{N}$, then the enterprise's core competence and the intrinsic value of the core assets are set respectively as $m$ and $n$, so when $M$ turns into $N, m$ turns into $n$. Enterprises enters new markets through innovation, so the author set the market size of the original market as $Q_{1}$, and set the market size for the new market as $Q_{2}$.

Under the premise of no intend, the enterprises directly apply the original core assets (core 
asset 1) to develop new products and enter new market (market 2) market to create profits. Companies share core assets to realize the core assets of synergy in two different markets. But as a result of the original core competence is not suitable for new market, the original core asset will without the support of core competence in the market 2.Core competence $(\mathrm{m})$ will be gradual rigidity and damping in the absence of innovation. Set the attenuation coefficient is $\mathrm{p}$, and $0<p<1$. Then the intrinsic value of each unit of the enterprise core competence in t time is:

$$
m(t)=m(1-p)^{t}
$$

Core assets are transformed from enterprise core competence, then set percent conversion is $r$, so the internal price of core assets in 1 time is:

$$
n_{1}(t)=r m(1-p)^{t}
$$

Core assets in the new market decay because there is no core ability support, then set its attenuation coefficient is $\mathrm{q}$, and $0<q<1$. The intrinsic value for core assets in time is:

$$
n_{2}(t)=r m(1-p)^{t}(1-q)^{t}
$$

As the core assets are simultaneously in two different markets, the two of the intrinsic value of core assets in the market is the accordant:

$$
n_{1}(t)=n_{2}(t)=r m(1-p)^{t}(1-q)^{t}
$$

Therefore, the profits are created by the enterprise in the two markets is:

$$
E_{1}=Q_{1} r m \sum_{t=1}^{\infty}(1-p)^{t}(1-q)^{t}=Q_{1} r m \frac{(1-p)(1-q)\left[1-(1-p)^{t}(1-q)^{t}\right]}{1-(1-p)(1-q)}
$$

Look for the limit of form(2.1.1):

$$
\lim _{t \rightarrow \infty} E_{1}=\lim _{t \rightarrow \infty} Q_{1} r m \frac{(1-p)(1-q)\left[1-(1-p)^{t}(1-q)^{t}\right]}{1-(1-p)(1-q)}=Q_{1} r m \frac{(1-p)(1-q)}{1-(1-p)(1-q)}
$$

As well:

$$
E_{2}=Q_{2} r m \sum_{t=1}^{\infty}(1-p)^{t}(1-q)^{t}=Q_{2} r m \frac{(1-p)(1-q)\left[1-(1-p)^{t}(1-q)^{t}\right]}{1-(1-p)(1-q)}
$$

Look for the limit of form(2.1.2):

$$
\begin{aligned}
& \lim _{t \rightarrow \infty} E_{2}=\lim _{t \rightarrow \infty} Q_{2} r m \frac{(1-p)(1-q)\left[1-(1-p)^{t}(1-q)^{t}\right]}{1-(1-p)(1-q)}=Q_{2} r m \frac{(1-p)(1-q)}{1-(1-p)(1-q)} . \\
& \lim _{t \rightarrow \infty} E_{1}+\lim _{t \rightarrow \infty} E_{2}=\left(Q_{1}+Q_{2}\right) r m \frac{(1-p)(1-q)}{1-(1-p)(1-q)} .
\end{aligned}
$$

\section{Impact of core competence cannibalize on the enterprise diversification expansion}

Enterprises cannibalize driven by the original intention of the core competence to create a 
new core competence. Enterprises innovate a new core competence into core asset (core asset 2) to develop new products to enter the market 2 to create profits through the domination process. Enterprise applicants different core assets in two markets completely, so the enterprise did not realize the core assets together with. While the core asset 2 which is applied by enterprise on the market 2 have the support of core competence, so it comes true that the core abilities are together with each other by sharing the two different core competence. Set the compatibility degree of enterprise's core competence and market as $k, 0 \leq k \leq 1$.

The value of enterprise core competence at the moment of $t$ is still:

$$
m(t)=m(1-p)^{t}
$$

The value of the core assets 1 at the moment is still:

$$
n_{1}(t)=r m(1-p)^{t}
$$

the intrinsic value of the core assets to market 2 :

$$
n_{2}(t)=k r m(1-p)^{t}
$$

profit for enterprises in original market:

$$
E_{1}^{\prime}=Q_{1} r m \sum_{t=1}^{\infty}(1-p)^{t}=Q_{1} r m \frac{(1-p)\left[1-(1-p)^{t}\right]}{p}
$$

Look for the limit of form(2.2.1):

$$
\lim _{t \rightarrow \infty} E_{1}^{\prime}=\lim _{t \rightarrow \infty} Q_{1} r m \frac{(1-p)\left[1-(1-p)^{t}\right]}{p}=Q_{1} r m \frac{1-p}{p}
$$

Profit for enterprises in the market 2 is:

$$
E_{2}^{\prime}=Q_{2} k r m \sum_{t=1}^{\infty}(1-p)^{t}=Q_{2} k r m \frac{(1-p)\left[1-(1-p)^{t}\right]}{p}
$$

Look for the limit of form(2.2.2):

$$
\begin{aligned}
& \lim _{t \rightarrow \infty} E_{2}^{\prime}=\lim _{t \rightarrow \infty} Q_{2} k r m \frac{(1-p)\left[1-(1-p)^{t}\right]}{p}=Q_{2} k r m \frac{1-p}{p} \\
& \lim _{t \rightarrow \infty} E_{1}^{\prime}+\lim _{t \rightarrow \infty} E_{2}^{\prime}=\left(Q_{1}+Q_{2} k\right) r m \frac{1-p}{p}
\end{aligned}
$$

Under the premise the will of the strong willingness of cannibalize, enterprises will damage the original core competence and create the enterprise in new market so that get a good adaptability, so the enterprise core ability and market 2 has a high degree of compatibility. So here set $\mathrm{k}=1$, so: $\quad \lim _{t \rightarrow \infty} E_{1}^{\prime}+\lim _{t \rightarrow \infty} E_{2}^{\prime}=\left(Q_{1}+Q_{2}\right) r m \frac{1-p}{p}(k=1)$

Under the premise of $\mathrm{k}=1$ comparing two cases of enterprise innovation performance: 


$$
\frac{\lim _{t \rightarrow \infty} E_{1}^{\prime}+\lim _{t \rightarrow \infty} E_{2}^{\prime}}{\lim _{t \rightarrow \infty} E_{1}+\lim _{t \rightarrow \infty} E_{2}}=\frac{\left(Q_{1}+Q_{2}\right) r m \frac{1-p}{p}}{\left(Q_{1}+Q_{2}\right) r m \frac{(1-p)(1-q)}{1-(1-p)(1-q)}}=1+\frac{q}{p-p q}
$$

Since $0<p<1$ and $0<q<1$, so $\frac{q}{p-p q}>0$, namely

$$
\lim _{t \rightarrow \infty} E_{1}^{\prime}+\lim _{t \rightarrow \infty} E_{2}^{\prime}>\lim _{t \rightarrow \infty} E_{1}+\lim _{t \rightarrow \infty} E_{2}
$$

Therefore, it can be seen, enterprise core ability cannibalize can improve innovation performance by improve compatibility degree of the core ability and new markets.

\section{Conclusions}

Enterprise core ability cannibalize can improve innovation performance by improve compatibility degree of the core ability and new markets, so as to improve innovation performance. By comparing the calculated results of Enterprises innovation performance in both cases, it can be concluded that with no core ability enterprise can improve the core competence for improving the new market compatible degree of the enterprise to create higher.

Therefore, the enterprise can improve the core ability in diversified expansion by improving the compatibility degree of core competence and new markets. In particular, according to the structure dimension of the willingness of cannibalize and intend to enterprise resources and practice two aspects of enterprise core competence and right: through to the change of business investment in equipment, key personnel in the enterprise resource transformation and training and complete the enterprise resources, improve the technical ability of companies to develop new products; through the enterprise practice and make suitable for new product development of organizational structure and system. And it will come from the enterprise itself, is reflected by the enterprise top managers. So develop the executives' willingness of cannibalize should start from now, so it makes the enterprise senior management personnel is willing to improve the core competitiveness of enterprises through the core ability and achieve higher performance in the market in the presence of new business opportunities or external competition pressure.

\section{References}

[1] Mason C H, Milne G R. An approach for identifying cannibalization within produce line extensions and multi-brand strategies.Journal of Business Research, 1994, 31(2-3):163-170.

[2] Chandy R K, Tellis G.J. Organizing for radical product innovation: the overlooked role of willingness to cannibalize.Journal of Marketing Research, 1998, 35(4):474-487.

[3] Deshpande R, Webster Jr F E. Organizatinoal culture and marketing defining the research agenda.Journal of Marketing, 1989, 53(1):3-5.

[4] Montalvo C. What triggers change and innovation?.Technovation, 2006, 26(3):312-323. 